\title{
Phenological response of vegetation to upstream river flow in the Heihe Rive basin by time series analysis of MODIS data
}

\author{
L. Jia ${ }^{1,2}$, H. Shang ${ }^{1,3}$, G. Hu ${ }^{1}$, and M. Menenti ${ }^{3}$ \\ ${ }^{1}$ State Key Laboratory of Remote Sensing Science, Jointly Sponsored by the Institute of Remote Sensing Applications of \\ Chinese Academy of Sciences and Beijing Normal University, Beijing, 100101, China \\ ${ }^{2}$ Alterra, Wageningen University and Research Centre, Wageningen, The Netherlands \\ ${ }^{3}$ Delft University of Technology, Delft, The Netherlands
}

Received: 31 May 2010 - Published in Hydrol. Earth Syst. Sci. Discuss.: 5 July 2010

Revised: 17 February 2011 - Accepted: 6 March 2011 - Published: 25 March 2011

\begin{abstract}
Liquid and solid precipitation is abundant in the high elevation, upper reach of the Heihe River basin in northwestern China. The development of modern irrigation schemes in the middle reach of the basin is taking up an increasing share of fresh water resources, endangering the oasis and traditional irrigation systems in the lower reach. In this study, the response of vegetation in the Ejina Oasis in the lower reach of the Heihe River to the water yield of the upper catchment was analyzed by time series analysis of monthly observations of precipitation in the upper and lower catchment, river streamflow downstream of the modern irrigation schemes and satellite observations of vegetation index. Firstly, remotely sensed NDVI data acquired by Terra-MODIS are used to monitor the vegetation dynamic for a seven years period between 2000 and 2006. Due to cloud-contamination, atmospheric influence and different solar and viewing angles, however, the quality and consistence of time series of remotely sensed NDVI data are degraded. A Fourier Transform method - the Harmonic Analysis of Time Series (HANTS) algorithm - is used to reconstruct cloud- and noise-free NDVI time series data from the Terra-MODIS NDVI dataset. Modification is made on HANTS by adding additional parameters to deal with large data gaps in yearly time series in combination with a Temporal-Similarity-Statistics (TSS) method developed in this study to seek for initial values for the large gap periods. Secondly, the same Fourier Transform method is used to model time series of the vegetation phenology. The reconstructed cloud-free NDVI time series data are used to study the relationship between the water availability (i.e. the
\end{abstract}

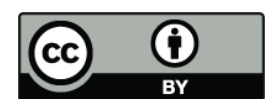

Correspondence to: L. Jia

(li.jia@wur.nl) local precipitation and upstream water yield) and the evolution of vegetation conditions in Ejina Oasis from 2000 to 2006. Anomalies in precipitation, streamflow, and vegetation index are detected by comparing each year with the average year. The results showed that: the previous year total runoff had a significant relationship with the vegetation growth in Ejina Oasis and that anomalies in the spring monthly runoff of the Heihe River influenced the phenology of vegetation in the entire oasis. Warmer climate expressed by the degreedays showed positive influence on the vegetation phenology in particular during drier years. The time of maximum green-up is uniform throughout the oasis during wetter years, but showed a clear S-N gradient (downstream) during drier years.

\section{Introduction}

The Heihe River is the second largest inland river in the northwest (NW) China, it originates from the Qilian Mountains in Qinghai province, runs through the Hexi Corridor of Gansu Province and flows into the western Inner Mongolian Plateau (Fig. 1). Liquid and solid precipitation is abundant in the high elevation, upper reach of the river, which yields sufficient runoff to the lower reach. The mid and lower reaches of the Heihe River, located in an arid and semi-arid climate environment, are characterized by very limited precipitation. The economy, agriculture and human living conditions in the Heihe River basin are therefore highly dependent on the streamflow of the Heihe River. Groundwater, replenished by local precipitation and water flow from the upstream catchment, also plays an important role in the eco-hydrological cycle of the lower reach. However, in the last thirty years, due

Published by Copernicus Publications on behalf of the European Geosciences Union. 

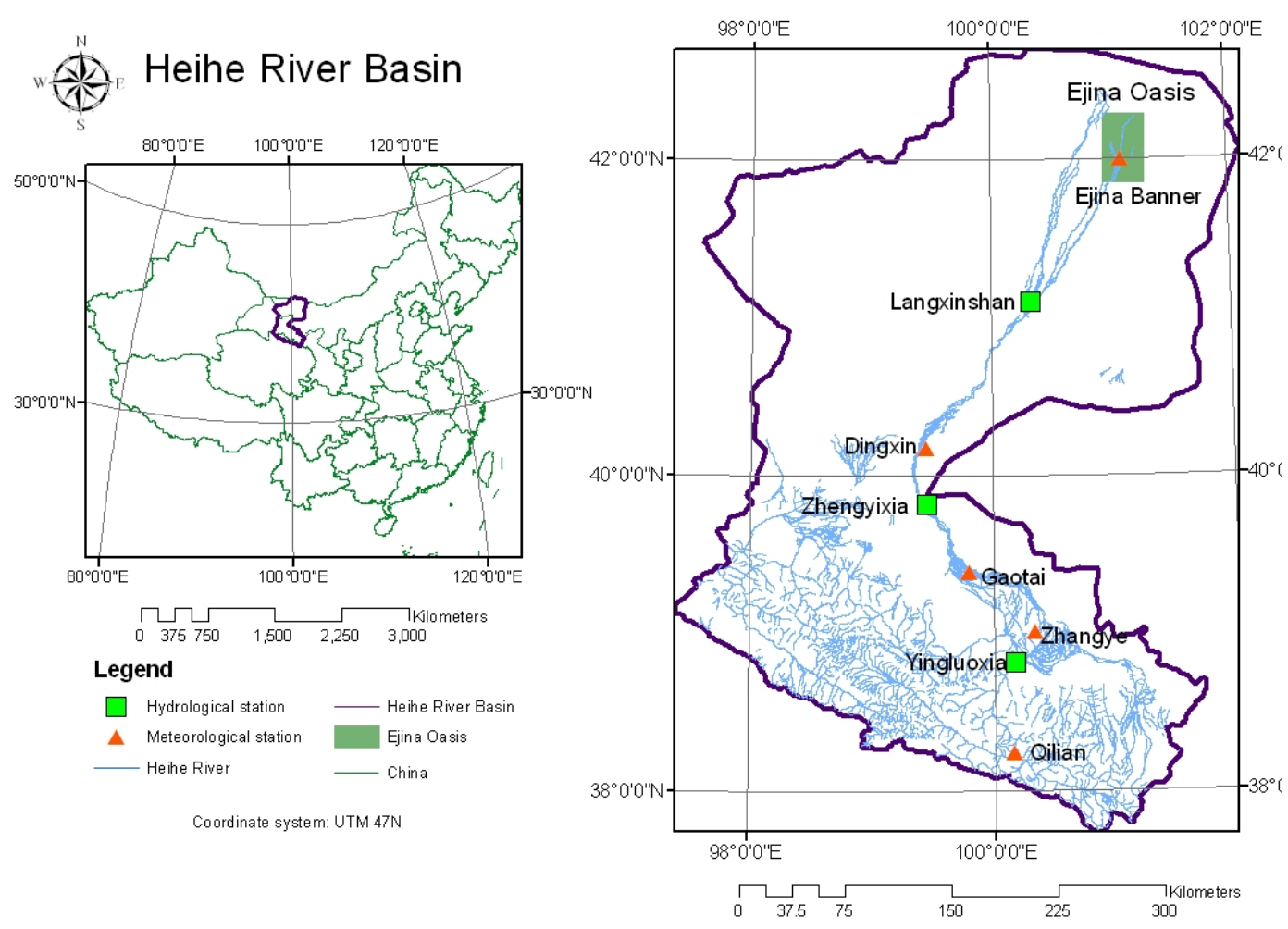

Fig. 1. The study area, meteorological stations and hydrological stations in Heihe River basin.

to the large increase of population and the fast development of economy, the water competition between human activities and nature became more and more serious, particularly in the middle and lower reaches. The development of modern irrigation schemes in the middle reach of the basin is taking up an increasing share of fresh water resources, endangering the oasis and traditional irrigation systems in the lower reach, the Ejina oasis (Fig. 1). The natural vegetation in this area has significantly decreased since 1990s and the desertification became more and more serious in the lower reaches of the Heihe River. A better understanding of the relationship between vegetation growth and the water availability could help managing the limited water resources more efficiently and protect the vulnerable biosphere along the Heihe River.

Satellite remote sensing data has been successfully applied to monitor and study vegetation dynamic and land cover changes (Bewket, 2002; Justice and Hiernaux, 1986; Zomer et al., 2001). The Normalized Difference Vegetation Index (NDVI) assumes that the difference between the near-infrared and red reflectance divided by the sum of both is a quantitative measure of photosynthetic activity. The NDVI is a quantitative description of vegetation conditions directly obtained from satellite remote sensing data and is widely used in many different application fields, for example, drought assessment (e.g. Liu and Negron Juarez, 2001), agricultural productivity assessment (e.g. Groten and Ocatre, 2002; Maselli and Rembold, 2001), climate linkages (e.g. Roerink et al., 2003; Wen et al., 2004) and so on. Recently, with the growing collections of satellite remote sensing data, the analysis of NDVI time series data has paved the way towards the study of phenological variations during a relatively long time period.

In order to understand the evolution of vegetation in response to water availability and the causes of phenological variations, a high temporal resolution is preferable in the NDVI time series. Optical remote sensing measurements are influenced by the atmosphere, clouds, bi-directional effects, the solar elevation angle and so on, thus the time series of NDVI data contain erroneous observations which need to be identified and removed. This yields gaps either in space or in time. Cloud contamination is the major factor affecting NDVI since lower NDVI are observed under hazy conditions and very low or negative values are observed when cloudy. Such cloud-contaminated observations are not easily identified and removed from the original data. Cloudiness not only reduces the reliability of NDVI data, but also makes it unfeasible to obtain a continuous NDVI time series for a long time over a large area. In addition, inadequate atmospheric correction might introduce noise, which would lead to errors in data analysis and interpretation. To reduce the occurrence of cloud-contaminated observations, most NDVI data sets are Maximum Value Composite (MVC) products (Holben, 1986), such as the Pathfinder AVHRR dataset and the SPOT VGT dataset. Such data products are generated 
by selecting and retaining the maximum NDVI value observed in each pixel during a certain period. This method can significantly improve the quality of the NDVI time series, but it cannot completely remove the noise due to cloudcontamination.

To reduce the noise and generate a cloud-free NDVI time series for data analysis, a number of methods have been developed and have been successfully applied in some cases. Some examples include the Best Index Slope Extraction algorithm (BISE) (Viovy et al., 1992; Lovell and Graetz, 2001) for analysis of daily NDVI data, the Asymmetric Gaussian function (Jonsson and Eklundh, 2002), a SavitzkyGolay filtering algorithm (Chen et al., 2004), the Mean-Value Iteration filter (MVI) (Ma and Veroustraete, 2006a), and the weighted least-squares linear regression to the temporal NDVI signal (Swets et al., 1999), among others. Even though these algorithms have been successfully used in many different applications, limitations need to be mentioned. For instance, the length of the sliding window and threshold value in BISE method may need to be adapted to different phenological stages and for different plant species. The weighted least-squares linear regression and the Asymmetric Gaussian function could not capture the complex phenology of land cover characterized by two or more growth cycles in one year. The reliability of the Savitzky-Golay filtering algorithm strongly depends on the assumption that the envelope of the original data gives the best description of vegetation growth, while this concept may lead to overestimate of the NDVI values, which are in most cases generated using the MVC method. When two or more adjacent cloud contaminated NDVI values occur, many iterations with the MVI method are required to estimate a reliable NDVI value.

Besides the methods mentioned above, the Discrete Fourier Transform was also used in NDVI time series analysis. The signal for each individual pixel can be decomposed into its Fourier components, such as series of harmonic sine or cosine waves, from which a cloud-free signal can be reconstructed (Menenti et al., 1993, 1995; Verhoef, 1996; Azzali and Menenti, 2000). In the Fourier transform of NDVI time series, the term harmonic implies that the time series is periodic. The assumption that the natural variation can be reproduced by a periodic model was inspired by the fact that time series of yearly and daily datasets of remotely sensed images often clearly displayed the influence of the yearly and diurnal courses of the sun on the earth's surface. The actual signals were not purely periodic, but the periodic model could be successfully applied to obtain useful insights in the dynamics of land surface processes. So it was widely used to study the linkages between climate and vegetation dynamic (e.g. Roerink et al., 2003; Wen et al., 2004; Immerzeel et al., 2005; Julien et al., 2006). Different algorithms were developed, i.e. the Fast Fourier Transformation (FFT) (Menenti et al., 1993) and Harmonic ANalysis of Time Series (HANTS) (Verhoef, 1996). The HANTS algorithm was developed to deal with time series of irregularly spaced observations and to identify and remove cloud-contaminated observations. The Fourier analysis problem was formulated as a curve fitting problem, so that it was possible to reject certain observations by attaching a weight of zero to them. The parameters describing the curve were determined by a weighted least squares fitting. Once the model is determined using the reliable (cloud-free) observations only, it can be used to fill the gaps generated by removing the cloud-contaminated observations.

The objective of this research was to study the vegetation dynamics in the Ejina Oasis, located in the terminal zone of the lower reach of the Heihe River basin in response to water availability, including both local rainfall and water flow from the upper and mid reaches, with particular attention to the significant inter-annual and intra-annual variability. Since the Ejina Oasis is located in the inland delta of the Heihe River basin, different hydrological processes contribute to determine vegetation phenology: local but scarce rainfall, water flow through the channel system in the delta and water flow through the shallow unconfined aquifer. As regards the latter, further complexity is added by the role of capillary rise and root water uptake, which both depend on soil type and on the depth of the shallow groundwater. We used one Fourier-Transform method - Harmonic Analysis of Time Series (HANTS) algorithm - to reconstruct time series of cloud-free NDVI data and analyze the vegetation responses to the water availability in the lower reaches of the Heihe River. The HANTS algorithm has some limitation when dealing with large gaps (a large number of contiguous missing data). Modification was therefore made on HANTS by adding additional parameters to deal with the condition with large gaps in yearly time series. A Temporal-SimilarityStatistics (TSS) method developed in this study to seek for initial values for the large gap periods before HANTS can be applied for large gap condition.

\section{Study area and data}

\subsection{Study area}

The study area is the arid and semi-arid land in Ejina Oasis, located in the lower reach of the Heihe River basin in northwest China (Fig. 1) across Qinghai, Gansu and Inner Mongolia Provinces. The top-left corner of the study area is $42^{\circ} 16^{\prime} 46.64^{\prime \prime} \mathrm{N}, 101^{\circ} 34^{\prime} 25.98^{\prime \prime} \mathrm{E}$, and the bottom-right corner $41^{\circ} 50^{\prime} 6.85^{\prime \prime} \mathrm{N}, 101^{\circ} 16^{\prime} 27.55^{\prime \prime} \mathrm{E}$, which is shown in Fig. 1. Ejina Oasis is the largest oasis in the lower reach of the Heihe River, characterized by a typical continental arid climate, with annual precipitation less than $100 \mathrm{~mm}$ (Wang and Cheng, 1999), mean annual pan evaporation larger than $3500 \mathrm{~mm}$ (Jin et al., 2008), and annual mean sunshine time duration of 3000 to $4000 \mathrm{~h}$ (Ma and Veroustraete, 2006b). The natural vegetation is fragmented and easily disturbed in this area. Figure 2 shows the land cover in the Ejina Oasis 
Table 1. Descriptions of the Vegetation Index (VI) Quality Assessment (QA) Science Data Sets (adopted from MOD13 User Guide).

\begin{tabular}{llcl}
\hline Bit No. & Parameter name & $\begin{array}{c}\text { Bit } \\
\text { combination }\end{array}$ & Description \\
\hline \multirow{3}{*}{0 to 1} & VI Quality & 00 & VI produced with good quality \\
& (MODLAND & 01 & VI produced but with unreliable quality and thus examination of other QA bits recommended \\
& Mandatory QA Bits - & 10 & VI produced but contaminated with clouds \\
& MODLAND_QA) & 11 & VI not produced due to bad quality \\
\hline
\end{tabular}

according to the data set provided by the Environmental and Ecological Science Data Center for West China, National Natural Science Foundation of China (http://westdc.westgis. ac.cn) in 2004. Shrubland and grassland are the major land cover types in Ejina Oasis. There are some dry croplands near the Heihe River. The grassland and the cropland are the main economic resource in the Ejina Oasis. The forest land consists of Poplar (P. Euphratica).

The Heihe River is the only water resource in the Ejina Oasis, which flows from the Qilian mountain, through the Hexi Corridor and flows into Inner Mongolia. The Yingluoxia gauge station and the Zhengyixia gauge station (Fig. 1) are located at the upper boundary of the mid and lower reach of the Heihe River respectively. The river divides into an Eastern and Western branches past the Langxinshan station. The water flow reaching the lower reach is strongly dependent on the water consumption in the mid reach, where the irrigation system is well developed. After the construction of water reservoirs and water diversion infrastructure, water supply to the Ejina Oasis has been significantly reduced. Regulation of river flow through the operation of reservoirs led to the degeneration of vegetation and desertification in the Ejina Oasis (Qi and Luo, 2006).

\subsection{Data}

\subsubsection{Satellite data}

In this research, we used the Normalized Difference Vegetation Index (NDVI) extracted from Terra-MODIS MOD13A2 products (MODIS Terra Vegetation Indices 16-Day L3 Global $1 \mathrm{~km}$ SIN Grid V005). The MODIS Vegetation Indices (VI) products are designed to provide consistent spatial and temporal distributions of vegetation conditions of the land surface at 1-km spatial resolution with 16-day interval. The MODIS Vegetation Index products are retrieved accurately using a state of the art MODIS specific, quality driven, constrained view angle, maximum value composite method, and the NDVI data are computed from atmospherically corrected bi-directional surface reflectances that have been masked for water, clouds, heavy aerosols, and cloud shadows. Multiple observations (more overpasses per day and more days) are required to generate each 16-day composited VI. Data from each 16-day period are first filtered
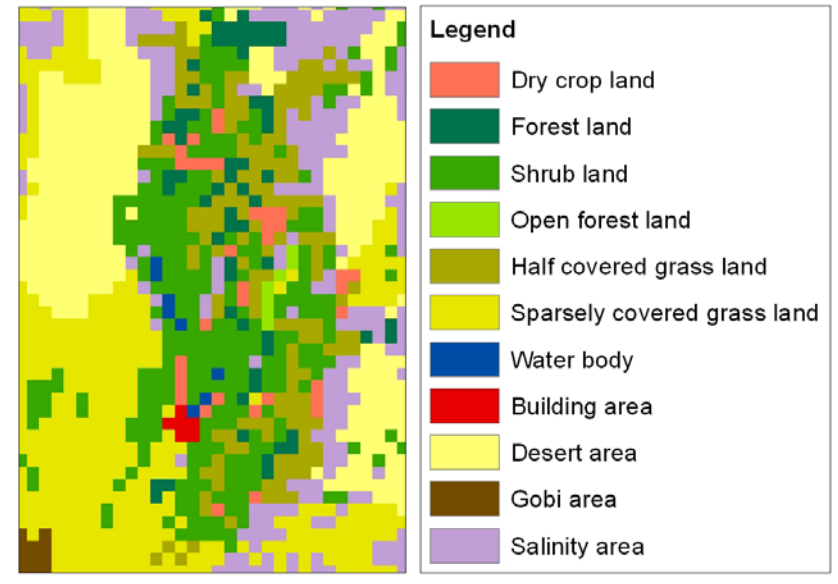

Fig. 2. Land cover map of the Ejina Oasis in 2004 (data provided by the Environmental and Ecological Science Data Center for West China, National Natural Science Foundation of China (http://westdc.westgis.ac.cn).

based on quality, cloud, and viewing geometry, only cloudfree, higher quality data will be used for composition.

Three separate compositing components are utilized in MOD13A2 to generate each one of 16-day composites in a yearly observation series (see detailed description in "MOD13A User Guide"): the maximum value composite (MVC) approach, the constrained-view angle - maximum value composite (CV-MVC) approach, and bidirectional reflectance distribution function composite (BRDF-C) approach. The BRDF-C approach requires at least five good quality observations available for a given pixel to derive nadir interpolated reflectance values from which the VIs are computed. The CV-MVC approach is the second choice if less than five acceptable values with good quality are available. The MVC technique is taken as the backup in case the first two approaches do not work, which assumes the pixel with the highest VI value to be most representative over the 16day period and marked by less than optimal data quality. In this way, the NDVI value in a given pixel is still generated for a 16-day composite as long as the data are qualified to meet the MVC condition, even though clouds contamination may still affect the data product. On the other hand, spatial discontinuities, say gaps in NDVI time series, 
are inevitable if no acceptable observations are available over a 16-day period which is usually the case due to local climate characteristics. With the use of data having less than optimal data quality, noise may still be observed and results in less accurate characterization of vegetation phenology. Nevertheless, as stated in the "Products Quality Documentation for MOD13A2 Collection 5", "for most cloud and snow free, low aerosol load pixels, the VI values are very reliable. (http://modis-250m.nascom.nasa.gov/cgi-bin/ QA_WWW/detailInfo.cgi?prod_id=MOD13A2\&ver=C5).

In MOD13A2, for each 16-day composite image there are 12 Science Data Sets (SDS) layers including NDVI and the Quality Assessment (QA) layer, the latter documents conditions under which the 16-day composite VI value is processed on a pixel-by-pixel basis. The general data quality is ranked according to the four levels given in Table 1.

The assessment on the quality of the MODIS NDVI data in the lower reach of the Heihe River basin will first be evaluated and the results will be given in Sect. 4.1 together with the performance of the time series reconstruction algorithm.

The data used in this study covers the period from 2000 to 2008 and downloaded from the Land Processes Distributed Active Archive Center (LP DAAC) (http://lpdaac.usgs.gov/).

\subsubsection{Meteorological and hydrological data}

Besides the remote sensing data sets, we also used meteorological and hydrological data from the Heihe River basin. There are five weather stations along the Heihe River (Fig. 1), which are Dingxin, Gaotai, and Zhangye in Gansu Province, Ejina Banner in Inner Mongolian Province, and Qilian in Qinghai Province. The Ejina Banner station is located in Ejina Oasis and was considered to represent the precipitation conditions in the study area, while Dingxin is located at the start of the lower reach (just after the Zhengyixia station along the river) (Fig. 1). Data from these two stations will be used in this study. The monthly precipitation was calculated from daily measurements at the two meteorological stations from 1952 to 2007.

The hydrological data was collected from two hydrological stations located at the start and at the end of the mid reach, just upstream of the Ejina Oasis (Fig. 1). The monthly streamflow at each station was calculated from daily measurements from 1978 to 2004.

\section{Methodology}

\subsection{Construction of gap free time series of NDVI observations}

\subsubsection{HANTS algorithm}

The HANTS algorithm (Menenti et al., 1993; Verhoef et al., 1996; Roerink et al., 2000) is based on the concept of discrete Fourier Transform. If a time series of $N$ samples of a variable $y$ is given with $y_{i}$ indicating the $i$-th sample of the series $(i=1, \ldots, N)$, then the sample $y_{i}$ can be described by means of a Fourier series:

$y_{i}=a_{0}+\sum_{j=1}^{M} a_{j} \cos \left(\omega_{j} t_{i}-\varphi_{j}\right)$

where $\omega_{j}$ is the frequency of the $j$-th-harmonic term of the Fourier series, $t_{i}$ is the time at which the $i$-th sample was taken and $M$ is the number of the terms (frequencies) of the Fourier series $(M \leq N), a_{j}$ and $\varphi_{j}$ are the amplitude and the phase of the $j$-th-harmonic term, respectively. As the "zero" frequency has no phase and the cosine becomes one, the amplitude associated with the zero frequency, $a_{0}$, is equal to the average of the $N$ samples of the variable $y$.

In the HANTS algorithm the most important control parameter are the frequencies $\omega_{j}$ which are the most significant frequencies expected to be present in the time series of observations. After setting the number of frequencies $M$ and selecting the harmonic terms of frequencies $\omega_{j}$, the unknown parameters of the Fourier series are the amplitudes $a_{j}$ and the phases $\varphi_{j}$ values, which are determined by fitting the time series of observations.

HANTS handles the Fourier analysis as a curve fitting problem. To evaluate each observation in the time series, the HANTS was designed to assign weights to observations to account for their quality in general and for cloud contamination in particular. In the current version of HANTS, only two weights are assigned - either "1" (corresponding to "good" data) or " 0 " (corresponding to "bad" data, which identifies a "outliers"). To identify and remove cloud-contaminated NDVI observations, HANTS performs curve fitting iteratively: in the first step, the least squares curve fitting is performed using all data in the series. In the second step, the observations which deviate from the first curve more than a pre-defined threshold are removed by assigning a weight of zero. The remaining data are used to compute the least squares curve fitting again, and outliers are identified and removed again using the same threshold as in the first step. This iterative procedure is repeated until all the remaining observations are within the pre-defined threshold.

The reliability of the reconstructed NDVI time series also depends on the quality of the original time series of NDVI data. The quality of the observation time series depends, inter alia, on the proportion of missing observations, number of gaps, gap size (defined as a period with continuously missing data), location of the gaps, and retrieval quality of land surface parameters. A large fraction of missing data, especially a large gap size may result in an inaccurate reconstruction of the time series. When dealing with a yearly time series with such extended gaps at the beginning or end of the year in particular, it becomes challenging to assess the accuracy of the reconstructed time series. The standard HANTS algorithm was therefore improved to deal with such cases by adding additional parameters to account for the proportion of missing 
data and gap size in the time series. The modified HANTS algorithm was combined with the TSS algorithm developed in this study (see Sect. 3.1.3) to reconstruct cloud- and noisefree time series of NDVI. Examples with large missing gaps in the NDVI time series are given in Sect. 4.1 together with the performance of HANTS and the TSS algorithms.

\subsubsection{Implementation of HANTS and parameters determining performance}

To obtain a reliable fitting curve, seven essential parameters have to be specified to run the HANTS algorithm:

- Valid data range - the range of the input variables values. The values out of this range are assigned a weight of zero.

- Period - the temporal length of each term in the Fourier series;

- Number of Frequencies (NOF) - the number of harmonic terms. Complex time series data might need more terms (frequencies) in the Fourier series to get an accurate fit. The amplitude of the zero frequency term is the mean value of the valid observations in the time series.

- Direction of outliers - is used to indicate the direction of unreasonable values with respect to the current curve. In the HANTS algorithm, these unreasonable values are called "outliers". In a time series of NDVI observations cloud-contaminated observations usually have low NDVI values, i.e. the direction of "outliers" is set to "low" which means that a NDVI value in the time series smaller than the predefined threshold will be eliminated by giving a weight "zero" to it.

- Fit Error Tolerance (FET) - is the distance which identifies observations in the times series which deviates from the time series more than this distance as "outliers". If all the remaining observations are within a distance of FET from the fitting curve, the iterations will stop.

- Degree of Over Determinedness (DOD) - the minimum number of extra data points which have to be used in the curve fitting. The number of valid observations must always be greater than or equal to the number of parameters that describe the curve (defined by $2 \times \mathrm{NOF}-1$ ). In order to get a more reliable fit more data points than the necessary minimum should be included as specified by the DOD value.

There is no straightforward rule in the determination of these essential parameters, some practice is usually needed before getting optimal values. More application cases can be found in literature (e.g. Azzali and Menenti, 2000; Roerink et al., 2000; Wen et al., 2004; among others).

\subsubsection{Temporal-Similarity-Statistics (TSS) method to improve HANTS performance}

A two-step method was developed in this study to deal with long gaps (either a large fraction of missing data, or large gap size, or both), which is called Temporal-SimilarityStatistics (TSS) method. The method is based on historical data and finds the initial values in the available data record for each pixel to fill extended gaps. For each pixel, the algorithm compares the current year time series with the available historical data record to obtain initial values for large gap segments in the time series by searching the entire data record for the year closest to the one being reconstructed and extract from such year (or years) estimates of the segment being reconstructed. To do so, the NDVI time series for each pixel is re-arranged in an array as described below,

Year

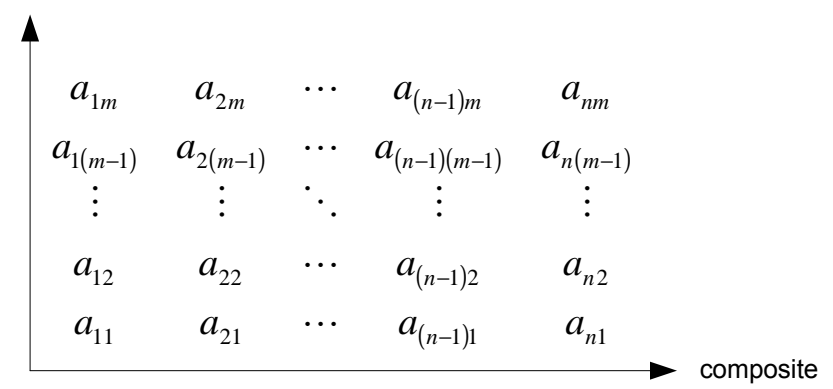

where the horizontal axis is the "composite" index in a given year (for instance with 16-day interval MOD13A2 version-5 product has 23 composites of NDVI in one year), while the vertical axis is the "year" index; i.e. $a_{k i}$ is the original NDVI value of the $k$-th composite $(k=1,2, \ldots, n, n$ is the total number of composites in one year time series) of the $i$-th year $(i=1,2, \ldots, m, m$ is total number of years in the dataset). The similarity in vegetation phenology between two years is then defined by the variance between the two years' time series of NDVI as written below

$C V_{i j}=\frac{\sum_{k=1}^{N}\left(a_{k i}-A_{k j}\right)^{2}}{N}$

where $C V_{i j}$ is the variance between the $i$-th year and the $j$ th year, $a_{k i}$ is the original NDVI of the $k$-th composite in the $i$-th year (referred to as the reference year), $A_{k j}$ is the HANTS reconstructed NDVI of the $k$-th composite in the $j$-th year (referred to the target year), $N$ is the number of the samples used to calculate the similarity of the two time series $(N<$ total number of composites in the original time series since composites corresponding to the large gaps are not considered). The year having the smallest $C V$ value will be used as the reference year, the composites in the reference year time series corresponding to the missing data segments in the target year will be taken as the initial estimates of these missing observations. 
This procedure is only applied when the gap is so large that will affect the reconstructed curve when using the standard HANTS algorithm. Experiments were done to evaluate the gap size (defined as a period with continuously missing data) in the time series that have significant influence on the reconstruction results of NDVI time series. The threshold gap size is correlated to the longest period (lowest frequency) considered in the Fourier series. The days of missing data should be less than half the longest period in the Fourier series, while the critical gap size is found to be around $10 \%$ of total sample numbers.

Once the initial values for the missing composites in the large gap segments are defined by the TSS approach, they are taken into the time series of the target year and HANTS is applied to the new time series to create the reconstructed time series curve of NDVI for the target year.

An alternative simple approach is to use the mean value of the historical data for the same composite. One potential problem is that vegetation phenology is affected by interannual variability in climate and water availability, in particular for the years with extreme conditions (e.g. drought or flood years). The advantage of the TSS approach is that it relies on phenological similarity over a full year to reconstruct large gaps.

\subsection{Intensity-Hue-Saturation (IHS) transform}

To analyze the vegetation growth condition especially the phase information, the IHS (Intensity, Hue, Saturation) transform was applied to the results obtained with the HANTS algorithm to display phenology by means of color combinations, while assuming that phenology is dominated by the yearly cycle. In the IHS transform, for each pixel, the mean value is assigned to the intensity component, the phase (of the yearly component) to the color hue, and the amplitude (of the yearly component) to the color saturation. The mapping of IHS onto the RGB (red/green/blue) representation is carried out using the following formulas (Verhoef et al., 1996; Julien et al., 2006):

$$
\begin{aligned}
& r=\frac{M-C}{S-C}\left[1+\frac{A}{A_{\max }} \cos (P-240)\right] \times 127 \\
& g=\frac{M-C}{S-C}\left[1+\frac{A}{A_{\max }} \cos (P-120)\right] \times 127 \\
& b=\frac{M-C}{S-C}\left[1+\frac{A}{A_{\max }} \cos P\right] \times 127
\end{aligned}
$$

here $r, g$ and $b$ are the color signals in red, green and blue, $M$ is the mean signal, $A$ is the amplitude, $P$ is the phase in degrees. The mean signal is scaled by the minimum value $C$ and a saturation value $S$. The amplitude is scaled between zero and a maximum value $A_{\max }$. Since we consider here only the yearly component of the Fourier series, the period is one year, the phase goes from $0^{\circ}$ and $360^{\circ}$ and $1^{\circ}$ corresponds to about 1 day.
In this study, the amplitude of the "zero frequency" of the Fourier series, e.g. the annual mean NDVI, was assigned to the intensity component. The amplitude of the 12-month term is found to be much larger in the Ejina Oasis area than those of the other three terms, the phase of the 12month term can be taken as the timing of the peak greenup and correlated to the color hue. The amplitude of the 12-month harmonic term is assigned to the color saturation. The order of the colors is therefore blue-cyan-greenyellow-red-magenta-blue, corresponding to the phase timing in the month of January-March-May-July-SeptemberNovember-January, respectively.

\subsection{Anomaly calculations}

The anomaly of annual precipitation and annual river streamflow was defined by

$\Delta V_{k}=V_{k}-\frac{\left[\sum_{i=1}^{N} V_{i}\right]}{N}$

where $k$ is the year number, $\Delta V_{k}$ is the anomaly of annual precipitation or river streamflow in the year $k, V_{k}$ is the annual precipitation or river streamflow in the year $k, \sum_{i=1}^{N} V_{i}$ is the sum of annual precipitation or river streamflow over the $N$ years.

The monthly anomaly of streamflow was calculated as

$\Delta Q_{j, k}=Q_{j, k}-\frac{\sum_{i=1}^{N} Q_{j}(i)}{N}$

where $j$ is the month number and $k$ is the year number, $\Delta Q_{k, j}$ is the month $j$ anomaly in year $k, Q_{k, j}$ is the monthly total streamflow in month $j$ and year $k$, and $\left[\sum_{i=1}^{N} Q_{j}(i)\right] / N$ is the mean monthly streamflow for month $j$ averaged over $N$ years (between 1980 and 2005) for the same month.

To calculate the yearly anomaly in NDVI, $V_{k}$ in Eq. (4) is replaced by annual mean value of NDVI.

\section{Results}

\subsection{Evaluation of the time series reconstruction algorithm}

Due to its arid/semi-arid climate, in the Ejina Oasis yearly cloud coverage is relatively small, and large gaps were very rare. Figure $3 \mathrm{a}$ gives the statistics of the cloudy condition masked as "10 - VI produced but contaminated with clouds" as assigned in the MOD13A2 QA data (see Table 1) in 2001, the worst year in the period 2000 through 2008. NDVI with cloud contamination may have much smaller values compared with its "true value". Continuous false low values are 

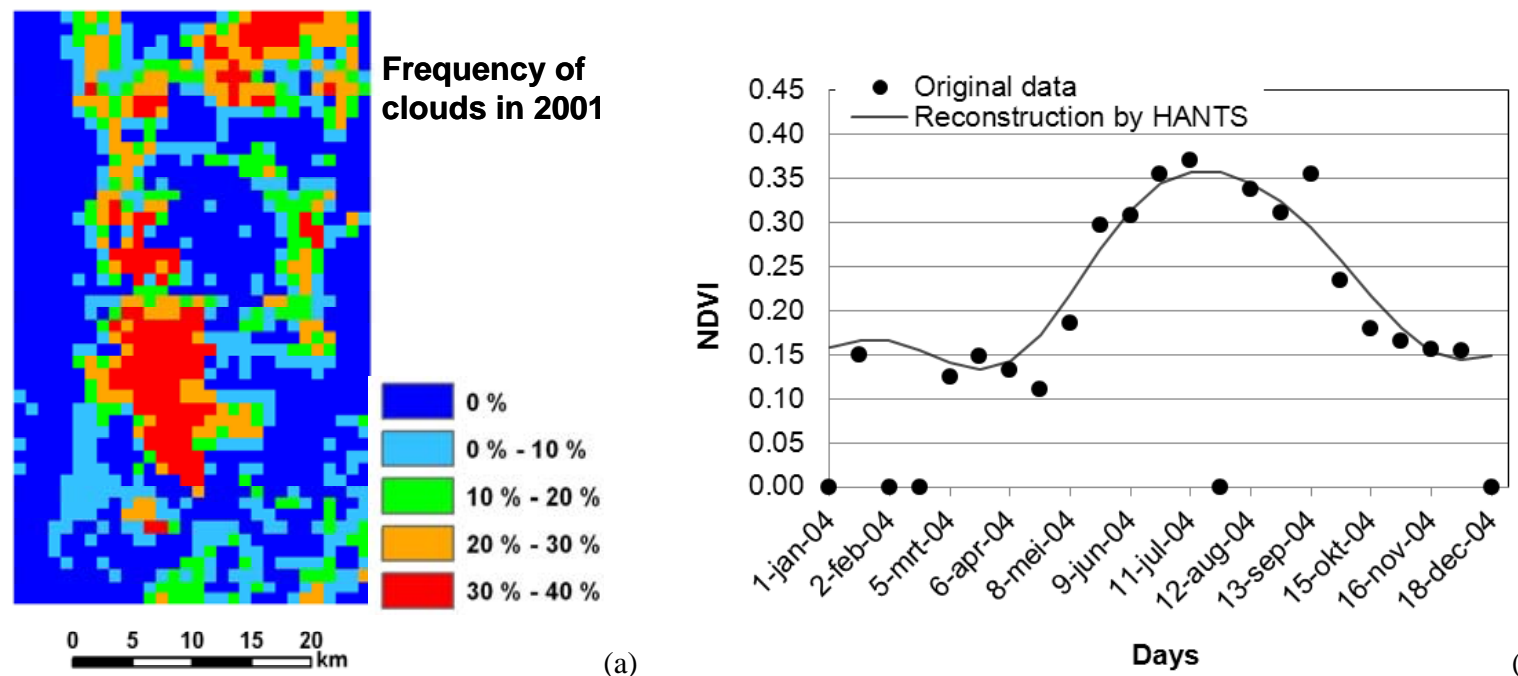

(a)

Days

(b)

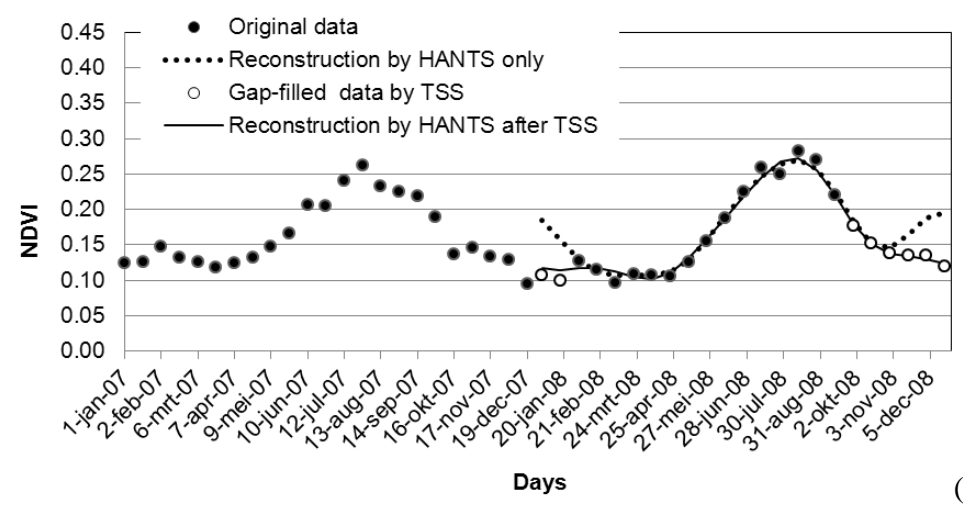

Fig. 3. Evaluation of TSS and HANTS algorithms: (a) percentage of cloudy days in 2001; (b) reconstructed curve is based on the original data with large gaps in the beginning of the year; (c) reconstructed curve is based on the filled dataset by TSS algorithm, large gaps in the beginning of the were initially filled by TSS algorithm.

similar to large gaps, both must be treated by TSS algorithm before applying HANTS to generate the reconstructed time series.

We have chosen two samples of the NDVI time series: one in the area with the medium cloud frequency about $20 \%$ over the year (green area in Fig. 3a) and one in the area with highest cloud frequency about $37 \%$ over the year (red area in Fig. 3a). We have then compared the actual data, the time series reconstructed with TSS, with HANTS and with HANTS after applying TSS (Fig. 3b, c). The results suggest that the performance of HANTS is adequate for the case with medium (around 20\%) cloud frequency. There are cases (Fig. 3c), especially when dealing with a single year time series when long gaps (or a long sequence of outliers) may occur either at the beginning or the end of the year. Reconstruction of the time series in such cases with HANTS only is difficult, since there is no information on the increasing (spring of the following year) or decreasing (autumn of the preceding year) segments. In these cases the TSS algorithm provides a satisfactory approximation (Fig. 3c).

\subsection{Analysis of hydrological conditions}

\section{Precipitation}

In the period from 1980 to 2007 the annual precipitation did not exceed $100 \mathrm{~mm}$ at Dingxin and $80 \mathrm{~mm}$ at Ejina Banner (Fig. 4a). The mean annual precipitation was $54 \mathrm{~mm}$ at Dingxin and $32 \mathrm{~mm}$ at Ejina Banner.

Anomalies calculated by Eq. (3) for each year's annual precipitation are presented in Fig. 4b. The annual precipitation in Ejina Banner showed a periodic oscillations in the last 28 years. From 1980 to 1989 , the annual precipitation at Dingxin and Ejina Banner was lower than the long term average in most of the years. From 1990 to 1999, more annual precipitation than the previous ten years was observed both at Dingxin and at Ejina Banner, in particularly in 1995 and 1999. Since 2000, the annual precipitation in Dingxin and Ejina Banner decreased significantly again, lower than the long-term average. 

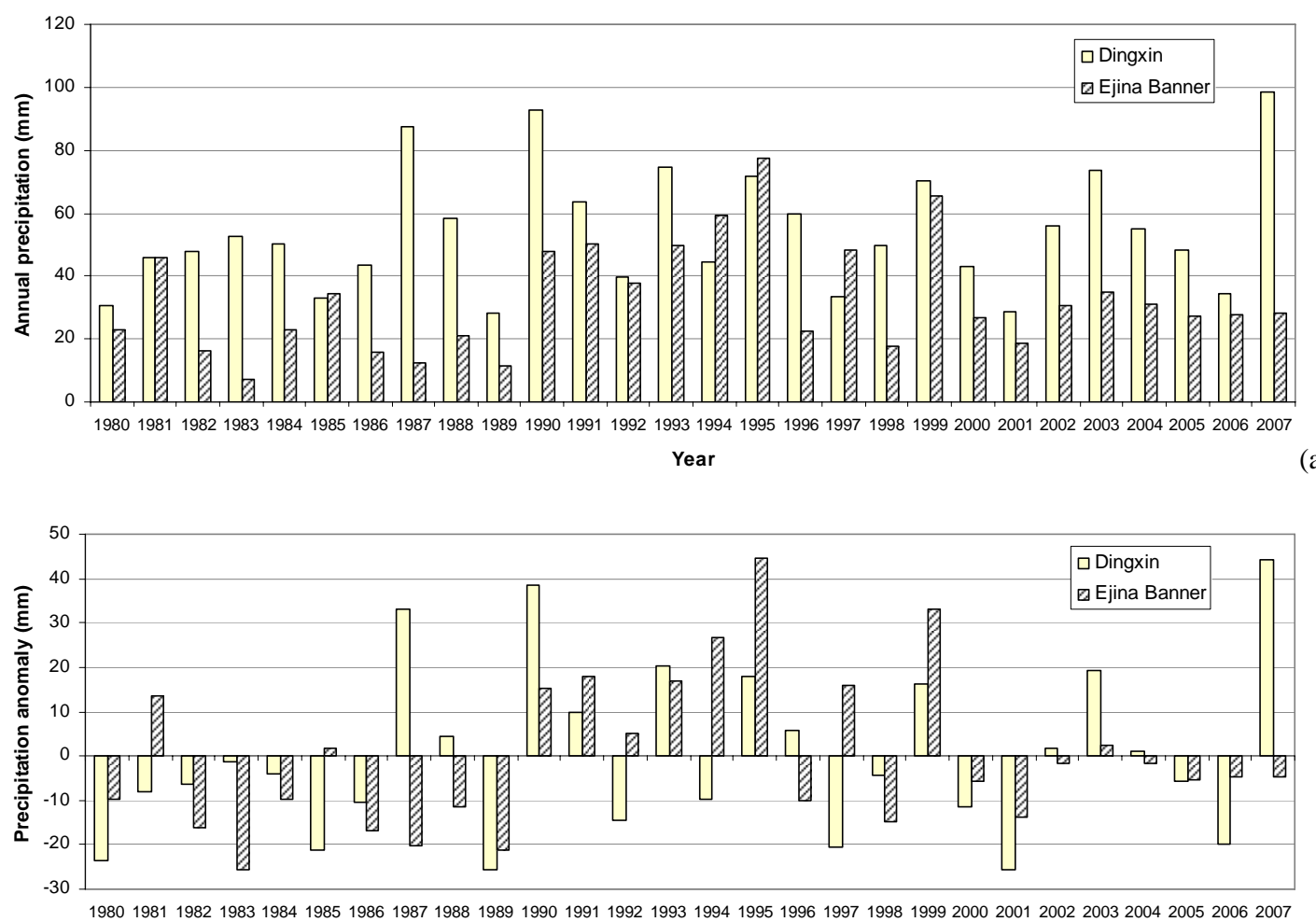

Year

Fig. 4. (a) The annual precipitation in Dingxin station and Ejin Banner stations from 1980 to 2007; ((b) the anomaly of the annual precipitations in Dingxin station and Ejina Banner station from 1980 to 2007.

Taking into account that mean annual potential evaporation in the same period was $3500 \mathrm{~mm}$ (Jin et al., 2008), we may conclude that the contribution of precipitation to water supply of vegetation in the Ejina Oasis is negligible.

\section{Streamflow}

The annual streamflow at Yingluoxia station, located at the start of the middle catchment area of the Heihe River basin, stayed at a relative high level with the 23 -years average of $1.65 \times 10^{9} \mathrm{~m}^{3}$ with standard deviation of $0.16 \times 10^{9} \mathrm{~m}^{3}$ (Fig. 5). However, the annual streamflow at Zhengyixia station, located at the end of the middle reach of the Heihe River, showed a significant decrease since 1990. Before 1990, the average of the annual streamflow at Zhengyixia was $1.11 \times 10^{9} \mathrm{~m}^{3}$ with standard deviation $0.5 \times 10^{9} \mathrm{~m}^{3}$, while it decreased to $0.75 \times 10^{9} \mathrm{~m}^{3}$ with standard deviation $0.17 \times 10^{9} \mathrm{~m}^{3}$ from 1990 to 2001 due to a significant increase in water demand in the middle reach areas of the Heihe River. The streamflow from the Heihe River supplied most of water consumed by the ecosystem in Ejina Oasis. The large decrease of streamflow from middle stream caused many environmental and ecological problems in the lower reach of the Heihe River basin, such as oasis desertification and vegetation degradation (Qi and Luo, 2006).
The monthly and annual anomalies of streamflow were calculated in the same way as the precipitation anomalies (Eqs. 2 and 5), respectively. The annual anomalies in streamflow at the two hydrological stations showed a synchronous increase or decrease in most years, but with different values, which indicated that the streamflow at Zhengyixia station highly depended on the streamflow at Yingluoxia station and the water consumption in the middle catchment of the Heihe River (Fig. 5b).

The monthly streamflow at Zhengyixia station in Fig. 6a showed that the discharge water from January to March was stable from 1998 to 2005 , higher than $7 \times 10^{7} \mathrm{~m}^{3}$. A sharp decrease in the streamflow was observed from April, reached its minimum in May and started to increase again in July. From May to June there was a cut-off of water supply to the Ejina Oasis from the Heihe River, this is mainly because irrigation in the agricultural area of the middle reach occurs in these months. The river had no continuous flow to the Ejina Oasis for more than 100 days per year since 1950 (Zhang et al., 2005). From July, the water supply from Zhengyixia station down to the Ejina Oasis increased again and reached the peak in the next three months. The streamflow decreased from October and increased in December again.

Large change of monthly streamflow mainly occurred between July and October as shown by the anomaly of the 


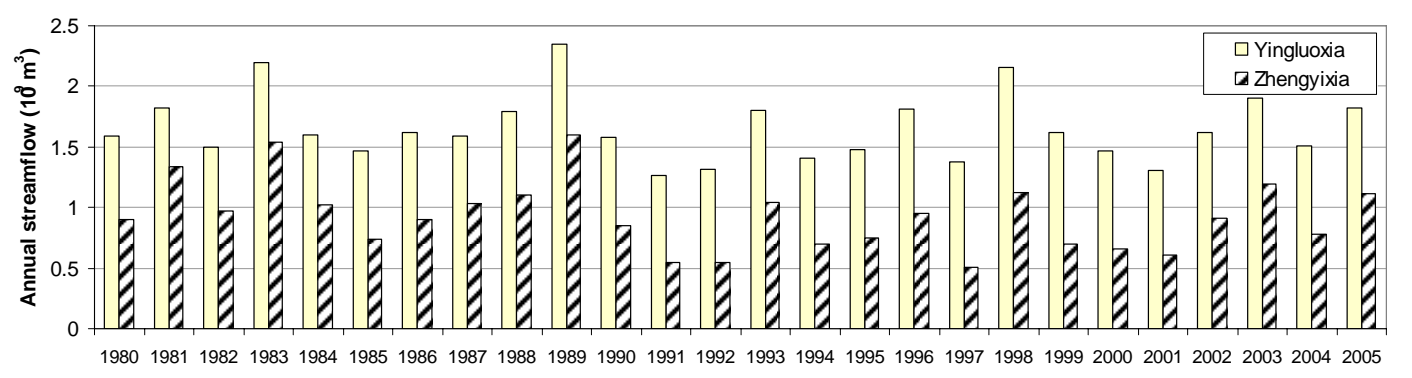

Year

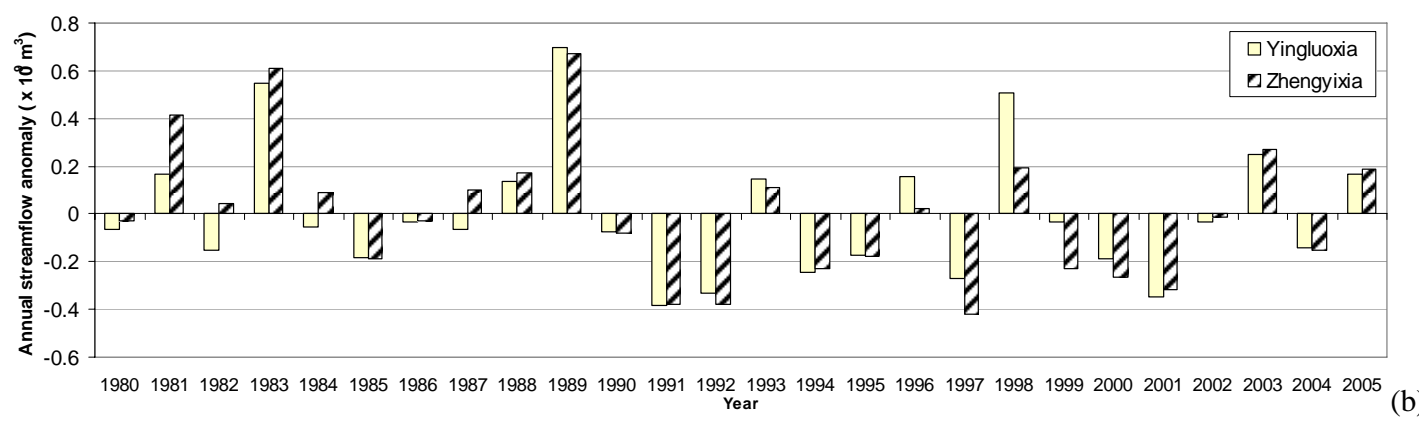

Fig. 5. (a) The annual streamflow and (b) the anomaly of the annual streamflow at Yingluoxia and Zhengyixia from 1980 to 2004.

monthly streamflow at Zhengyixia station in Fig. 6b. In 1999,2000 , and 2001, the anomaly of the streamflow in most months between July and October showed large negative values, implying that the vegetations in the Ejina Oasis might suffer from lack of water supply in these three years.

\subsection{Analysis of vegetation response}

\section{Annual mean area-averaged NDVI}

Vegetation in the Ejina Oasis depends critically on river flow released in the upper and middle reaches, past allocation and use for irrigation. The operation of reservoirs and of the irrigation infrastructure in the middle reach leads to a large intraannual variability in river flow released to the lower reaches (Fig. 6), characterized by sudden, short-lived increases in river flow. Large annual variability of the streamflow was characterized during few years by continuous negative annual anomalies in the streamflow (Fig. 5). In this section, the annual vegetation growth conditions were analyzed by linking observed phenology to the inter-annual and intra-annual fluctuations of the water yield from the upper stream of the Ejina oasis.

The amplitude of "zero frequency" of the Fourier components of the NDVI time series represents the annual mean value of NDVI. Analysis was focused on the vegetated land surface only by identifying pixels with land cover classes of forest, shrubs, sparsely covered shrubs and sparsely covered grassland, referred to as "oasis" in the following analysis. Desert and Gobi pixels were not considered. The areaaverage of annual mean NDVI of Ejina Oasis was therefore calculated by averaging the annual mean NDVI over the "oasis" pixels in the Ejina Oasis. Taking the Ejina Oasis as a whole, the difference between the drier conditions in the years 2000 through 2002 and wetter conditions in 2003 through 2006 is clearly reflected by the evolution of the annual mean NDVI (Fig. 7a). The vegetation condition was worst in 2001, while it did improve gradually and the best condition was observed in 2004 when the streamflow in the previous year (i.e. 2003) was the highest between 2000 and 2006 (Fig. 7a).

The timing of the vegetation green-up, i.e. peak NDVI, is one of the indicators of vegetation growth with respect to the influence of climate and water availability. The amplitude of the 12-month harmonic component was found much larger than the amplitudes of the 6-month and the 3-month harmonic components, the 12-month harmonic component therefore reflects the main growth cycle of the vegetation in the Ejina oasis. Hence, the phase value of the 12-month harmonic component of the Fourier Transform gives the timing of the peak green-up of the vegetation. A significant delay in the timing of peak green-up of the vegetation, characterized by a larger phase value of the 12-month harmonic, occurred in 2001, the driest year in the sample observed (Fig. 7b).

\section{Influence of water availability and climate on vegetation growth}

The time series of river flow and of the area-averaged monthly NDVI (Fig. 8) clearly shows that vegetation greenup trails river flow, but also shows no response of vegetation green-up to the intra-annual fluctuations in river flow. The 

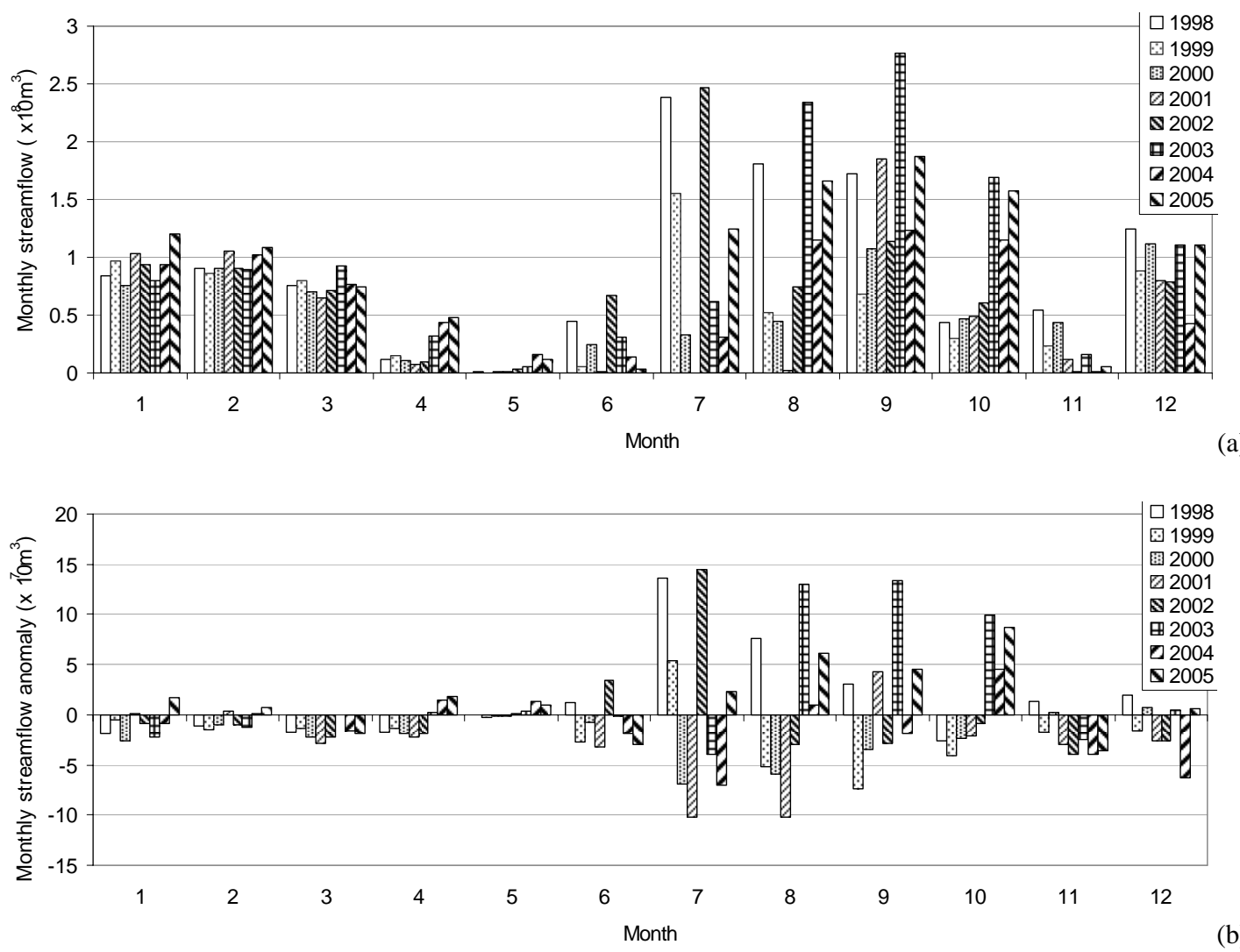

(b)

Fig. 6. (a) The monthly streamflow and (b) the anomaly of the monthly streamflow at Zhengyixia station from 1998 to 2004 (mean value was calculated between 1980 and 2005).
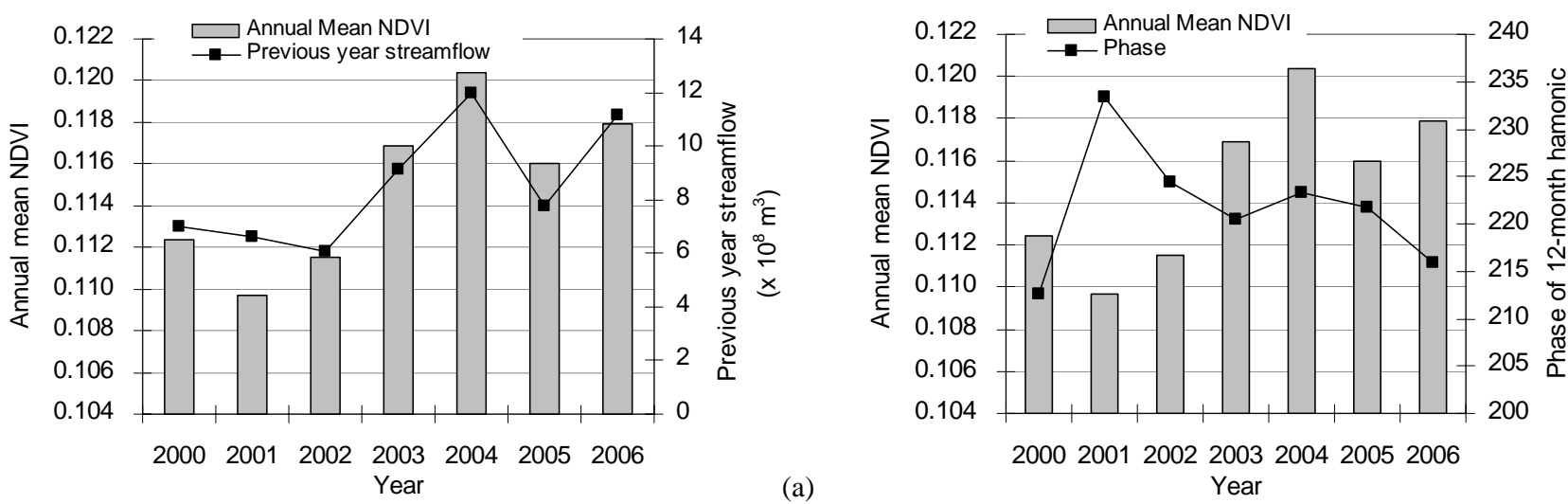

Fig. 7. Area-averaged annual mean NDVI and the previous year total river streamflow (a) and the phase value of 12-month Fourier harmonic component (b) between 2000 and 2006 in the Ejina Oasis of the Heihe River's lower reach. The phase value indicates the time of peak green-up of the vegetation.

estimation of the time lag between river flow and vegetation green-up and especially its inter-annual variability is of importance towards a better understanding of hydro-ecological processes in the Ejina Oasis.

The area-averaged annual mean NDVI values for the seven years between 2000 and 2006 were analyzed against the annual streamflow of the previous-2nd-year, the previous year and current year measured at the Zhengyixia hydrological station. A good correlation was found between the annual vegetation conditions and the previous-year streamflow $\left(R^{2}=0.86\right.$, significant at p-value $<0.01$, Fig. 9a), while no correlation between the annual mean NDVI and the current year total streamflow was found. Similar results were also found by Jin et al. $(2008,2009)$ who used the same 


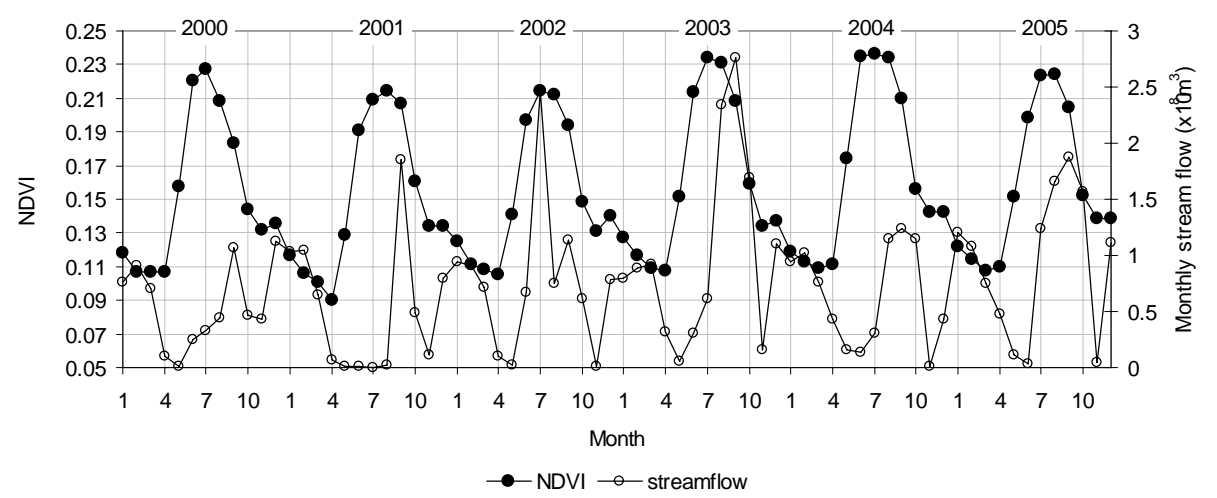

Fig. 8. Monthly total river streamflow at the Zhengyixia hydrological station and the area-averaged monthly NDVI between 2000 and 2005 in the Ejina Oasis.
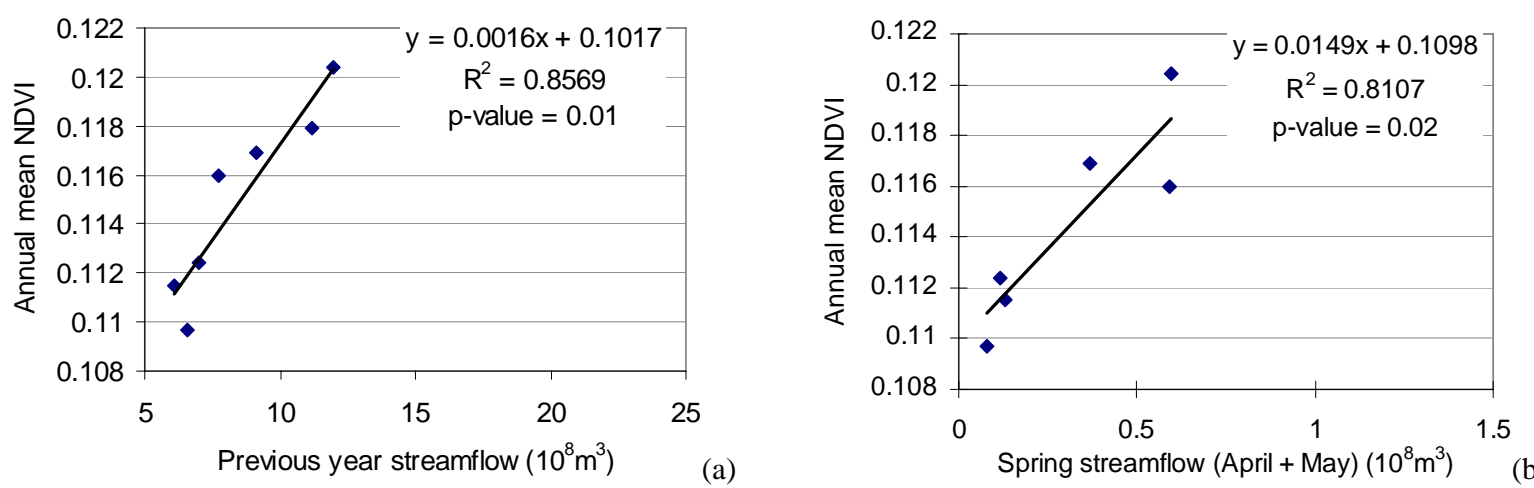

Fig. 9. (a) Area-averaged annual mean NDVI of year $N$ versus total river streamflow of year $(N-1)$; (b) area-averaged annual mean NDVI of year $N$ versus total river streamflow of March through May of year $N$.

MODIS data but limited to the growing season and without reconstructing cloud and noise-free time series. However, we have also analyzed the correlation between current year's spring streamflow (for different periods between March-April, April-May, May-June) and the yearly vegetation condition. We observed that the correlation with the streamflow of the current year's spring between AprilMay was significant $\left(R^{2}=0.81\right.$, significant at $\mathrm{p}$-value $<0.02$, Fig. 9b). Higher annual water yield from the upper stream of the Heihe River in the previous year might have provided sufficient water to recharge the groundwater in the downstream of the river, i.e. the Ejina Oasis. Both correlations imply a significant role of shallow groundwater in determining the delayed response of vegetation conditions to water supply.

Further analysis was done on the time lag between streamflow and vegetation green-up by using the phase value of the 12-month harmonic. A plot of the area-averaged phase value versus previous year streamflow reveals two completely different patterns (Fig. 10a): the timing of the peak green-up increased by up to about 25 days (i.e. a $25^{\circ}$ increase in the phase value) over the dry years $(2000,2001,2002)$ with a slightly negative, but similar anomaly in streamflow in the previous year, with the largest delay in the peak green-up observed in the driest year (i.e. 2001). At higher streamflow, no clear relationship is observed between the phase value and the previous year's streamflow. Similar results were observed when considering streamflow in the spring of the current year (Fig. 10b).

Here we have evaluated an additional indicator of phenology, i.e. the air temperature sum (i.e. accumulated degreedays) over the growing season, which is the main determinant of the duration of phenological stages. The duration of phenological stages is determined by the duration of sustained higher air temperature, specifically measured by the sum of air temperatures exceeding a species (variety) specific threshold and expressed in degree-days. Here the air temperature sum was calculated using a generic base-temperature of $10^{\circ} \mathrm{C}$, estimated from the base temperature values given in Baldocchi (2010) and Wikipedia (http://en.wikipedia.org/ wiki/Growing-degree_day). The results show (Fig. 11) that increasingly higher values are obtained under increasingly drier conditions (2001 and 2002) (see also Figs. 4, 5 and 7) and that an earlier peak green-up and lower values of the temperature sum were observed under wetter conditions (2003 through 2005). The shorter duration of the vegetative development (i.e. the time to peak green-up) in 2000 was clearly 

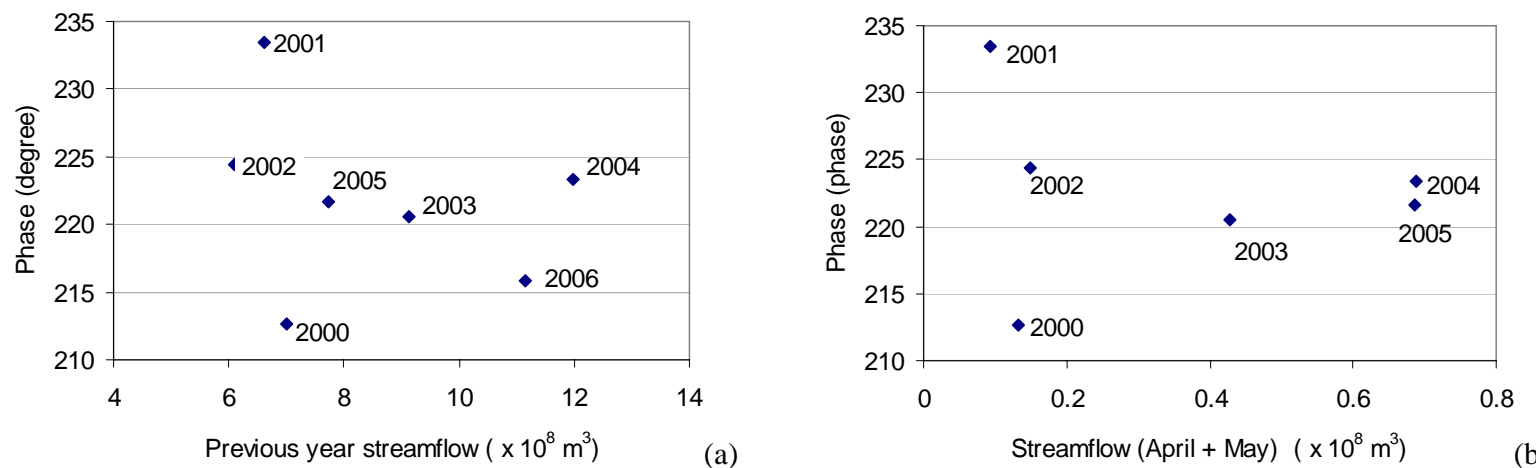

Fig. 10. (a) Area-averaged phase value of 12-month Fourier harmonic component of year $N$ versus total river streamflow of year $(N-1)$; (b) area-averaged phase value of 12-month component of year $N$ versus total river streamflow of April through May of year $N$. The river streamflow was measured at the Zhengyixia gauge station.

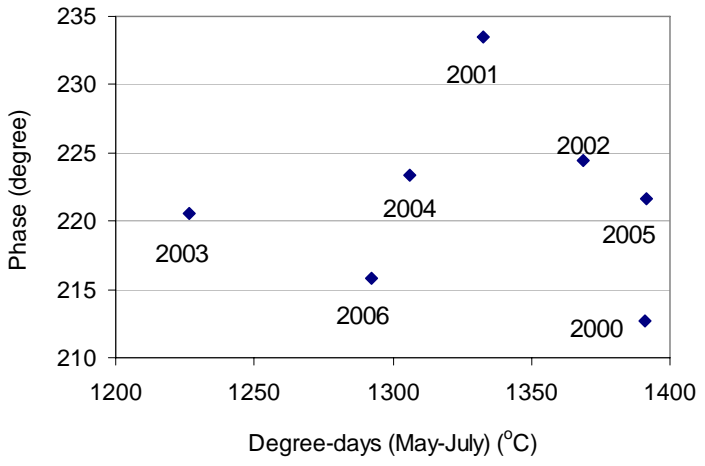

Fig. 11. Area-averaged phase value of 12-month Fourier harmonic component versus degree-days for May through July between 2000 and 2006.

associated with the largest temperature sum observed during the years (i.e. from 2000 to 2006) considered in this study (Fig. 11), It should also be noted that the time to peak greenup (i.e. the phase value) increases from 2000 to 2002 and 2001, consistently with the temperature sum which decreases from 2000 to 2002 and 2001 under conditions of comparably low streamflow.

\section{Spatial variability of vegetation growth conditions}

Using IHS color transform described in Sect. 3.2, timing of the peak green-up in different years can be mapped. Since the river streamflow data collected at the Zhengyixia gauge station were only available till 2005, the analysis and discussion on the vegetation response to the water availability in Ejina Oasis of the downstream catchment of the Heihe River were mainly limited to the period between 2000 and 2006, even though IHS maps till 2008 are displayed in Fig. 12.

In an IHS transform color image, light grey to white stands for a nearly constant high NDVI during the whole year, while dark refers to a constantly low NDVI, such as desert area.
The color hue indicates the appearing time of the maximum NDVI. In the Ejina Oasis, the vegetation growth is usually between April and October. Thus if there was vegetation growing in the pixel, the color of the pixel should be in the range of green-yellow-red (see Eq. 3). The pixels with colors beyond this range are covered by desert or buildings. With the similar hue but different intensity, for example, one pixel with bright yellow, the other with dark yellow, the bright pixel would have a higher annual mean NDVI than the dark yellow one, but the timing of the peak green-up would be similar.

In Fig. 12, the area with black or dark blue around the Ejina Oasis is desert or Gobi around Ejina Oasis. Within the Ejina Oasis the peak green-up in most of the vegetated area appeared among July, August, and September (color from yellow, orange to red) from 2000 to 2008. The dark green area located between the Ejina Oasis and its surrounding desert area is a very sparsely covered area by vegetation. The blue area within the Ejina Oasis is probably the Heihe River or building area. The area with magenta indicates that the maximum NDVI appeared in October or November.

The timing of peak green-up did change in different years and it is discussed below:

In 2000, most pixels in Ejina Oasis had a yellow or orange color, which implies that the maximum NDVI in most vegetated area occurred in the mid July or beginning of August. In the north-west and south-east part of the oasis in 2000, brighter "yellow" color than any other years implies that in these areas vegetation was in the best conditions compared to other years.

In 2001, the color of most pixels changed to red, indicating that the timing of maximum greenness was significantly delayed to the end of August or beginning of September.

From 2002 to 2004, number of pixels with yellow and orange increased gradually, which indicated that the timing of maximum NDVI was earlier than that in 2001, shifted back to August or July. In 2002, "orange" and "red" were dominant colors, while in 2003 the "orange" was the dominant color 


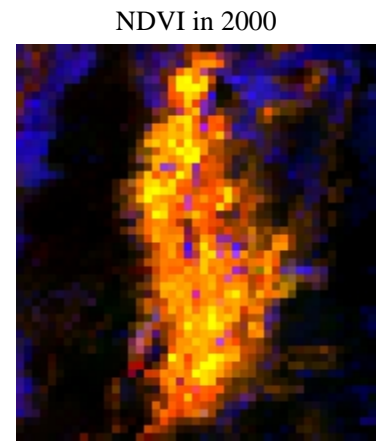

NDVI in 2003

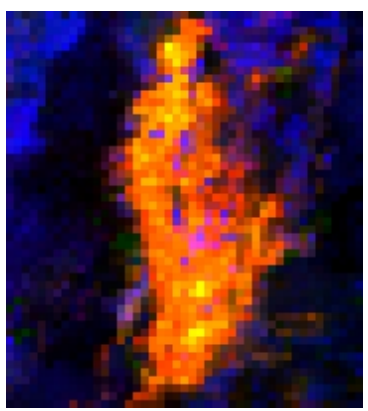

NDVI in 2006

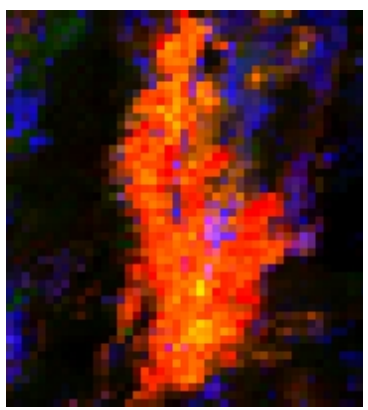

NDVI in 2001

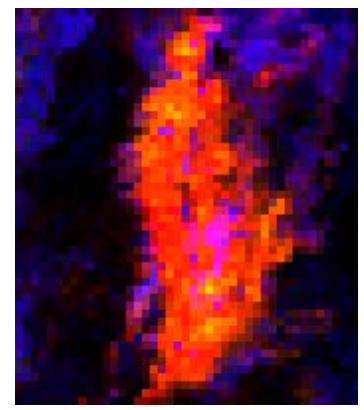

NDVI in 2004

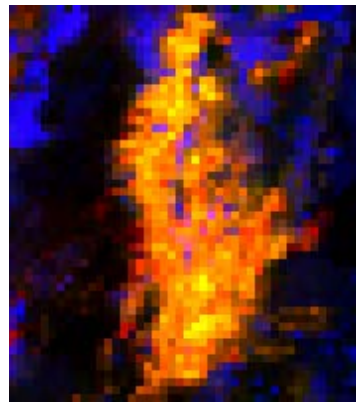

NDVI in 2007

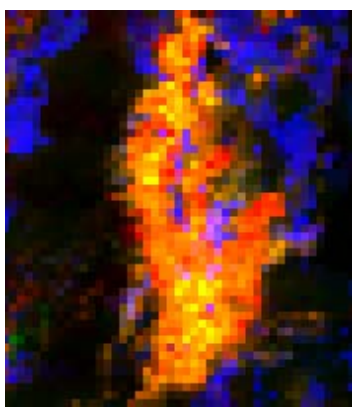

NDVI in 2002

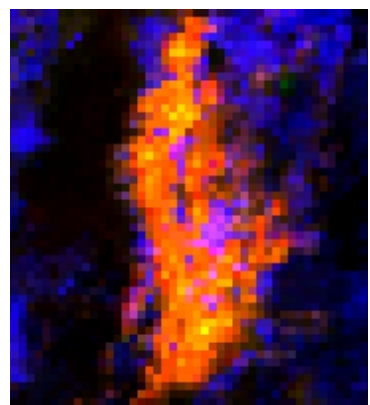

NDVI in 2005

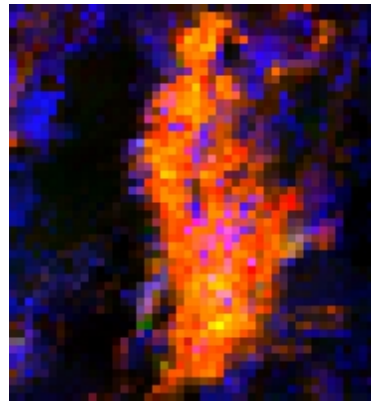

NDVI in 2008

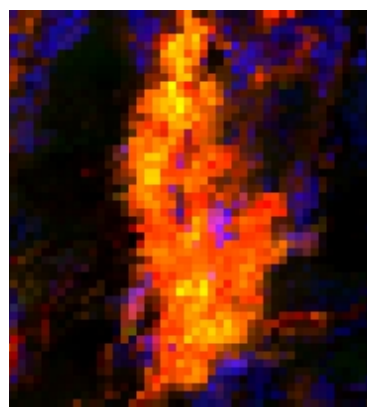

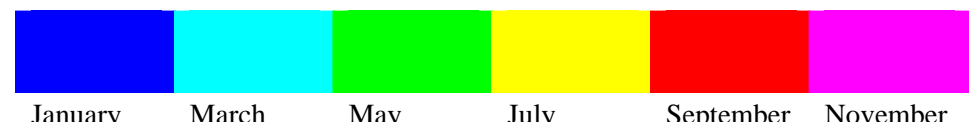

Fig. 12. The IHS color transformed image of the 12-month Fourier harmonic component of NDVI time series from 2000 to 2008 in the Ejina Oasis in the lower reach of the Heihe river basin. "Intensity" = annual mean NDVI, "Hue" = the phase of the 12-month harmonic component, "Saturation" = the amplitude of the 12-month harmonic component.

with a significant increase in the number of "yellow" pixels. In 2004, vegetation condition seems the best expressed by a large fraction of yellow pixels, the size of oasis area has also slightly increased when compared to 2000 .

Taking the Ejina Oasis as a whole, the sequence of the timing of peak green-up for the 9 years period is estimated as 2000-2007-2004-2008-2003-2005-2002-2006-2001.

To evaluate whether the South-North (S-N) propagation of the fluctuations in streamflow through the drainage channels and the shallow aquifer system had any influence on the timing of peak green-up, we calculated the mean phase value in a East-West direction, i.e. over all columns of the 12-month phase image for each row, and plotted such mean value in the
S-N direction, i.e. along the rows of the same image (Fig. 13). A significant gradient appears only in drier years (2001 and 2002) (see also Figs. 5, 7 and 10) and only in the northern portion of the Ejina Oasis. On the contrary, no gradient was observed in the wetter years (2000 and 2004).

The gradient in the northern portion of the Ejina Oases indicates a delay of about 20 days in the time of peak greenup over a distance of $15 \mathrm{~km}$. Given the results in Fig. 11, this is most likely due to a combined influence of insufficient surface and groundwater in the terminal section of the river and a gradient in temperature sum in the dry years, with increasingly higher values occurring towards the river terminal zone. A map of the air temperature sum, however, cannot 


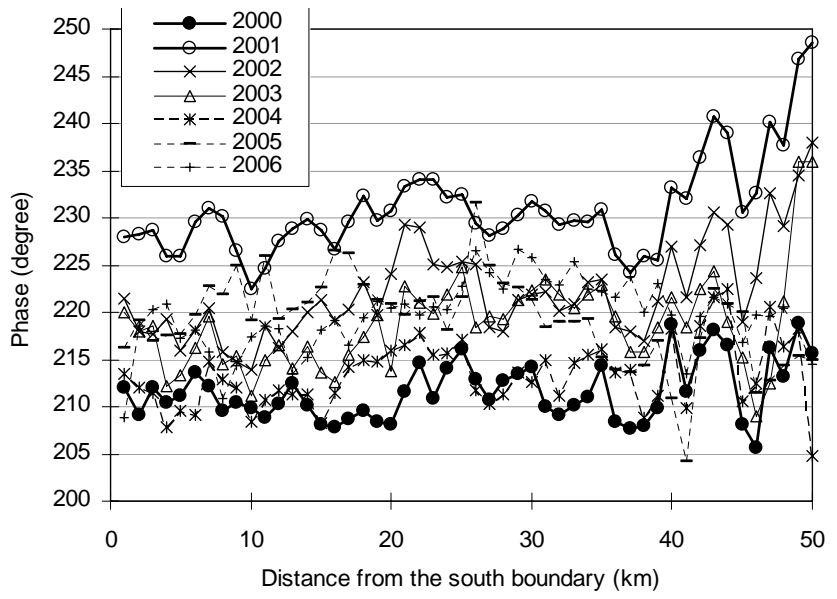

Fig. 13. Column-average of phase values of 12-month Fourier harmonic component of year $N$ versus row, i.e. S-N transect of oasis for each year $N$.

be constructed due to the absence of air temperature observations at different locations in the Ejina Oasis.

\section{Discussion}

As shown in Sect. 4, the annual vegetation growth is correlated with river streamflow upstream of the Ejina Oasis, both in the previous year and during the spring of the current year. This implies that river streamflow determines vegetation conditions through groundwater recharge and groundwater table depth, rather than by direct supply of river water. These interactions are discussed below to interpret the NDVI observations.

Even though the streamflow in 2000 had a negative anomaly at both stations (Fig. 5), the water yield from the upper catchment in 1998 was rather rich and local precipitation in the downstream area in 1999 was far above the long-term average. This explains that the mean annual NDVI in 2000 was close to the average for the entire period 2000-2006. In other words, vegetation conditions in 2000 were still good in comparison with 2001, although both precipitation and the streamflow showed very large negative anomalies in 2000. It should be noted that the air temperature sum is obviously determined by the current year evolution of weather conditions, so that the phenology of vegetation is determined by previous year hydrological conditions (most likely recharge of the shallow aquifer system) in combination with current year weather, most notably the air temperature sum.

Continuous rather low water yield from the upper stream in 1999 and 2000 (Fig. 5) and large negative anomaly for two years in local precipitation (2000 and 2001) (Fig. 4) resulted in 2001 in the worst vegetation growth condition during the period 2000-2006 as shown by the smallest annual mean NDVI and the delayed timing of peak green-up in 2001
(Fig. 7). Water yield from the upper stream in 2002 was larger thanks to the new water allocation plan launched by the local government and as a consequence, a significant improvement was observed in the vegetation conditions in the following year 2003 (Fig. 8). Intensive water releases from the upper reach to the lower reach of the river in 2003 and moderate precipitation in 2003 resulted in fairly good vegetation growth in 2004, although both the streamflow from upstream and local precipitation showed a negative anomaly in 2004.

The combined effect of previous year water supply and of current year air temperature sum is quite evident when considering the years 2000, 2001 and 2002 (see Figs. 7, 10a and 11). Water supply was relatively limited during these years, with previous year streamflow being larger in 2000, which was characterized by warmer weather as indicated by the higher air temperature sum. The period of vegetative growth was shorter, as indicated by the earlier peak greenup, but vegetative development was better than in both 2001 and 2002, because of more abundant water.

Conversely, when comparing 2000 with 2003 and 2004, we see that the effect of previous year streamflow was dominant: weather was significantly cooler, i.e. the temperature sum significantly lower, but overall vegetative development was significantly higher than average due to the positive anomaly in streamflow (Fig. 10a).

According to hydrological studies by Su et al. (2007) and Wen et al. (2005), the groundwater in the downstream area of the Heihe River is recharged mainly from the rapid seepage flow of river water. Observations have shown that the time of propagation of fluctuations in river flow through the shallow aquifer is determined by the distance to the river: up to $1 \mathrm{~km}$ from the river, where the shallow aquifer is recharged by current year's river flow. At distances between $1 \mathrm{~km}$ to $10 \mathrm{~km}$ from the river, the groundwater recharge is a combination of the historical recharge (since 1950s) and recent years' recharge (Wen et al., 2005).

These considerations, however, apply to the vicinity of each drainage channel. If we take the entire drainage system (see Fig. 1 in Akiyama et al., 2007) into account, we will have a combination of rapid propagation downstream along the drainage channels and slower outwards propagation from each drainage channel into the shallow aquifer. This mechanism is likely to explain the absence of time lag in peak green-up during the wetter years and the fact that a time lag does appear only in the northern, drier, portion of the Ejina Oasis and only in drier years (Fig. 13).

The depth of the shallow groundwater table fluctuates in response to fluctuations in streamflow, while dampening such fluctuations, which explains the absence of rapid fluctuations in the time series of the area-averaged NDVI. What needs to be evaluated in a future study is whether the amplitude of the fluctuations in groundwater table depth is as large as to have a significant impact on water uptake by roots and, therefore, on magnitude and timing of vegetation green-up. Here 
we can only estimate the critical range in shallow groundwater table depth. Zhu et al. (2009) studied the impact of fluctuations in groundwater table depth on water uptake by roots by means of numerical experiments performed with the model HYDRUS-1D and field experiments. In 2000 with average groundwater table depth at $2.64 \mathrm{~m}$, P.-euphratica, the dominant natural tree species in the area, obtained $53 \%$ of transpiration from groundwater during the central part of the growing season (DOY 160-290). The root vertical distribution was $10 \%$ in the top $60 \mathrm{~cm}, 60 \%$ between $60 \mathrm{~cm}$ and $1 \mathrm{~m}$, $25 \%$ between $1 \mathrm{~m}$ and $1.8 \mathrm{~m}$ and $5 \%$ between $1.8 \mathrm{~m}$ and $2 \mathrm{~m}$. Numerical experiments indicated that a deeper water table depth from $2 \mathrm{~m}$ to $3 \mathrm{~m}$ would reduce transpiration by $74 \%$. Deepening from $2.5 \mathrm{~m}$ to $3 \mathrm{~m}$ in groundwater level reduces transpiration from $1.5 \mathrm{~mm} \mathrm{~d}^{-1}$ to $0.5 \mathrm{~mm} \mathrm{~d}^{-1}$ during the central part of the growing season. Water flux from the groundwater table into the root zone was $300 \mathrm{~mm}$ with the groundwater table at $2 \mathrm{~m}, 150 \mathrm{~mm}$ with $2.5 \mathrm{~m}$ and $60 \mathrm{~mm}$ with $3 \mathrm{~m}$.

We can estimate the magnitude of the fluctuations in groundwater table depth on the basis of the observations of Akiyama et al. (2007) in the Ejina Oasis. They measured groundwater table depth daily for 14 months at three sites $20 \mathrm{~m}$ (Site 1), $300 \mathrm{~m}$ (Site 2) and $10 \mathrm{~km}$ (Site 3) from the river. Yearly amplitude of shallow groundwater table depth was slightly less than $2 \mathrm{~m}$ at Site 1 , less than $1 \mathrm{~m}$ at Site 2 and nearly zero at Site 3 , indicating fast recharge due to river water to at least $300 \mathrm{~m}$ from the river. Groundwater table depth was about $4 \mathrm{~m}$ at both Site 2 and Site 3. In Akiyama's study, estimated time of propagation of fluctuations in river flow was 60 days for a distance of $300 \mathrm{~m}$. The time lag estimated from the observations is about one month between Site 1 and 2 and several months between Site 1 and Site 3, although the very small seasonality at Site 3 makes this estimate less reliable. River water was observed occasionally at the river terminus during the non-irrigation months, while river water was present at the southern apex of the lower reaches during the non-irrigation periods.

Field observations in the Tarim Basin by Chen et al. (2006), Wang et al. (2007) showed non-stressed condition with water table at $3.82 \mathrm{~m}$, mild stress with $4.74 \mathrm{~m}$ water table and moderate stress with $5.82 \mathrm{~m}$. Similar studies in the Heihe indicated a shallower optimal groundwater table depth, in the range $2 \mathrm{~m}$ to $4 \mathrm{~m}$ (Liu et al., 2007).

We may then conclude that wherever the groundwater table depth drops from $2 \mathrm{~m}$ to $3 \mathrm{~m}$ say, a transition from wet, i.e. non limiting water supply, to dry, i.e. limiting water supply, conditions occur and we may expect to observe spatial variability in both magnitude and timing of vegetation greenup. Given the morphological and hydrological characteristics of the Ejina Oasis, this is more likely to occur in the northern portion of the Oasis. We may then tentatively explain the occurrence of the S-N gradient in the timing of vegetation green up by a decrease, say by $1 \mathrm{~m}$, in groundwater table depth in the northern portion during drier years, so as to reduce significantly plant transpiration and photosynthesis.
The observed gradient in the 12-month phase value in our study (Fig. 13) implies that during drier years the peak greenup of vegetation in the northern zone of the Ejina Oasis moves in S-N direction. This is consistent with the propagation of fluctuations in water supply: fast over longer distances through the drainage channels and slow over short distances through the shallow aquifer system. The literature evidence reviewed above suggest that "drier conditions", given the characteristics of the Ejina Oasis, means a decrease in groundwater table depth from $2 \mathrm{~m}$ to $4 \mathrm{~m}$, possibly just $3 \mathrm{~m}$. Accordingly, our hypothesis, to be verified by a dedicated observations program, is that during years with lower streamflow groundwater table depth reaches to about $3 \mathrm{~m}$ in the northern portion but not in the southern portion, thus explaining the clear S-N gradient in the timing of vegetation green-up.

\section{Conclusions}

This study provided new insights on the hydrological processes determining vegetation phenology in the Ejina Oasis by looking at time series of ground based observations of precipitation, air temperature and streamflow and of satellite observations of vegetation phenology.

The primary driver of vegetation development is previous year streamflow, modulated by streamflow in the spring of the current year. Both overall development of vegetation, as measured by the yearly mean NDVI value, and the timing of peak green up are affected, but weather in the current year has a significant impact on both the duration and magnitude of vegetative development. This conclusion is based on the observed temperature sum and the time lag estimated by Fourier analysis of the NDVI time series.

The observed spatial patterns in the timing of peak green up did reveal different mechanisms in the downstream propagation of fluctuations in streamflow. During wetter years no S-N (downstream) gradient in the timing of peak green up was observed, which is not consistent with propagation through the shallow aquifer only. Under these conditions fluctuations in streamflow propagate downstream through the drainage channels of the inland delta of the Heihe River and through the aquifer, During drier years a significant S-N gradient in the timing of peak green up appears in the northern portion of the Ejina Oasis. The latter is due to a combination of two processes: reduced recharge of the shallow aquifer and drawdown of the groundwater table depth beyond the reach of a large fraction of plant roots, thus leading to water stress and reduced growth.

Higher spatial remote sensing observations, for instance made by MODIS at $250 \mathrm{~m}$ pixel size, combined with the measurements of groundwater table may be helpful in a more detailed analysis of the spatial variation in relation to groundwater depth. The tentative conclusions drawn in this study on the relation between groundwater recharge, drawdown of the 
groundwater table depth and the S-N gradient in the timing of peak green up should be verified by field experiments designed to verify this hypothesis.

Acknowledgements. This work was jointly supported by the NSFC project (grant number 91025004), the EU-FP7 project CEOPAEGIS (grant number 212921), the project (KB-14-001-014) supported by the research program "Sustainable spatial development of ecosystems, landscapes, seas and regions" funded by the Dutch Ministry of Economic Affairs, Agriculture and Innovation, the "CAS 100-Talent Project" and the project of "CAS Visiting Professorship for Senior International Scientists", the ESA-MOST Dragon-2 project (5322). The authors would like to sincerely thank Environmental and Ecological Science Data Center for West China (http://westdc.westgis.ac.cn) for providing the hydrological data.

Edited by: X. Li

\section{References}

Akiyama, T., Sakai, A., Yamazaki, Y., Wang, G., Fujita, K., Nakawo, M., Kubota, J., and Konagaya, Y.: Surfacewatergroundwater interaction in the Heihe River basin, Northwestern China, B. Glaciol. Res., 24, 87-94, 2007.

Azzali, S. and Menenti, M.: Mapping vegetation-soil-climate complexes in southern Africa using temporal Fourier analysis of NOAA - AVHRR NDVI data, Int. J. Remote Sens., 21(5), 973996, 2000.

Baldocchi, D.: Lecture 4 Characterizing the Vegetation, Part 3: Geographic Distribution of Plants, Environmental Science, Policy and Management (ESPM) 129, BIOMETEOROLOGY: PlantEcosystem-Atmosphere Interactions, http://nature.berkeley.edu/ biometlab/espm129/ (last access: 25 October 2010), 2010.

Bewket, W.: Land cover dynamics since the 1950s in the Chemoga Watershed, Blue Nile Basin, Ethiopia, Mt. Res. Dev., 22, 263269, 2002.

Chen, J., Jonsson, P., Tamura, M., Gua, Z., Matsushitab, B., and Eklundhd, L.: A simple method for reconstruction a high-quality NDVI time-series data set based on the Savitzky-Golay filter, Remote Sens. Environ., 91, 332-344, 2004.

Chen, Y. N., Wang, Q., Li, W. H., Ruan, X., Chen, Y. P., and Zhang, L. H.: Rational groundwater table indicated by the ecophysiological parameters of the vegetation: A case study of ecological restoration in the lower reaches of the Tarim River, Chinese Sci. Bull., 51, 8-15, 2006.

Groten, S. M. E. and Ocatre, R.: Monitoring the length of the growing season with NOAA, Int. J. Remote Sens., 23, 2797-2815, 2002.

Holben, B. N.: Characteristic of maximum value composite images for temporal AVHRR data, Int. J. Remote Sens., 7, 1417-1434, 1986.

Immerzeel, W., Quiroz, R., and Jong, S.: Understanding precipitation patterns and land use interaction in Tibet using harmonic analysis of SPOT VGT-S10 NDVI time series, Int. J. Remote Sens., 26(11), 2281-2296, 2005.

Jin, X., Hu, G., and Wan, L.: Hysteresis effect of runoff of the Heihe river on vegetation cover in Ejin Oasis in Northwestern China, Earth Sci. Front., 15, 198-203, 2008.
Jin, X., Schaepman, M., Clevers, J., Su, Z., and Hu, G.: Correlation Between Annual Runoff in the Heihe River to the Vegetation Cover in the Ejina Oasis (China), Arid Land Res. Manag., 24(1), 31-41, 2009.

Jonsson, P. and Eklundh, L.: Seasonality extraction by function fitting to time series of satellite sensor data, Int. Geosci. Remote Sens., 40, 1824-1832, 2002.

Julien, Y., Sobrino, J. A., and Verhoef, W.: Changes in land surface temperatures and NDVI values over Europe between 1982 and 1999, Remote Sens. Environ., 103, 43-55, 2006.

Justice, C. O. and Hiernaux, P. H. Y.: Monitoring the grasslands of the Sahel using NOAA AVHRR data: Niger 1983, Int. J. Remote Sens., 7, 1475-1497, 1986.

Liu, P.-X., Peng, J.-F., and Chen, F.-H.: Hydrological Response of Populus euphratica Olve. Radial Growth in Ejinaa Banner, Inner Mongolia, J. Integr. Plant Biol., 49(2), 150-156, 2007.

Liu, W. T. and Negron-Juarez, R. I.: ENSO drought onset prediction in northeast Brazil using NDVI, Int. J. Remote Sens., 22, 34833501, 2001.

Lovell, J. L. and Graetz, R. D.: Filtering pathfinder AVHRR Land NDVI data for Australia, Int. J. Remote Sens., 22, 2649-2654, 2001.

Ma, M. and Veroustraete, F.,: Reconstruction pathfinder AVHRR land NDVI time-series data for the Northewest of China, Adv. Space Res., 37, 835-840, 2006a.

Ma, M. and Veroustraete, F.: Interannual variability of vegetation cover in the Chinese Heihe River Basin and its relation to meteorological parameters, Int. J. Remote Sens., 27, 3473-3486, 2006 b.

Maselli, F. and Rembold, F.: Analysis of GAC NDVI data for cropland identification and yield forecasting in Mediterranean African Countries, Photogramm. Eng. Rem. S., 68, 71-75, 2001.

Menenti, M., Azzali, S., Verhoef, W., and van Swol, R.: Mapping agroecological zones and time lag in vegetation growth by means of Fourier analysis of time series of NDVI images, Adv. Space Res., 13(5), 233-237, 1993.

Menenti, M., Azzali, S., and Verhoef, W.: Fourier analysis of time series of NOAA-AVHHR NDVI composites to map isogrowth zones, in: Climate change research: evaluation and policy implications, book on "Studies in Environmental Science", Vol. 65, edited by: Zwerver, S., van Rompaey, R. S. A. R., Kok, M. T. J., and Berk, M. M., Elsevier, Amsterdam, The Netherlands, 425430, 1995.

Qi, S. and Luo, F.: Land-use change and its environmental impact in the Heihe River Basin, arid northwest China, Water Environ. J., 21, 142-148, 2006.

Roerink, G. J., Menenti, M., and Verhoef, W.: Reconstructing cloudfree NDVI composites using Fourier analysis of time series, Int. J. Remote Sens., 21, 1911-1917, 2000.

Roerink, G. J., Menenti, M., Soepboer, W., and Su, Z.: Assessment of climate impact on vegetation dynamics by using remote sensing, Phys. Chem. Earth, 28, 103-109, 2003.

Su, Y. H., Feng, Q., Zhu, G. F., Si, J. H., and Zhang, Y. W.: Identification and evolution of groundwater chemistry in the Ejin SubBasin of the Heihe River, northwest China, Pedosphere, 17, 331342, 2007.

Swets, D. L., Reed, B. C., Rowland, J. D., and Marko, S. E.: A weighted least-squares approach to temporal NDVI smoothing, in: Proceedings of the American Society of Photogrammetric 
Remote Sensing, Portland, OR, USA May 1999, American Society of Photogrammetric Remote Sensing (ASPRS), Washington, DC, 526-536, 1999.

Verhoef, W.: Application of Harmonic Analysis of NDVI Time Series (HANTS), in: Fourier analysis of temporal NDVI in the Southern African and American continents, edited by: Azzali, S. and Menenti, M., Wageningen, The Netherlands, DLO Winand Staring centre, Report 108, 19-24, 1996.

Verhoef, W., Menenti, M., and Azzali, S.: A colour composite of NOAA-AVHRR NDVI based time series (1981-1992), Int. J. Remote Sens., 17, 231-235, 1996.

Viovy, N., Arino, O., and Belward, A.,S.: The best index slope extraction (BISE): a method for reducing noise in NDVI time series, Int. J. Remote Sens., 17, 1585-1590, 1992.

Wang, G. X. and Cheng, G. D.: Water resource use and its ecoenvironmental problems in arid zone of northwest China, J. Nat. Resour., 14, 109-116, 1999.

Wang, Q., Ruan, X., Chen, Y. N., and Li, W. H.: Eco-physiological response of Populus euphratica Oliv. to water release of the lower reaches of the Tarim River, China, Environ. Geol., 53, 349-357, 2007.
Wen, J., Su, Z., and Ma, Y.: Reconstruction of a cloud-free vegetation index time series for the Tibetan plateau, Mt. Res. Dev., 24, 348-353, 2004.

Wen, X., Wu, Y., Su, J., Zhang, Y., and Liu, F.: Hydrochemical characteristics and salinity of groundwater in the Ejina Basin, Northwestern China, Environ. Geol., 48, 665-675, 2005.

Zhang, Y. H., Wu, Y., Su, J., Wen, X., and Liu, F.: Groundwater replenishment analysis by using natural isotopes in Ejin Basin, Northwestern China, Environ. Geol., 48, 6-14, 2005.

Zhu, Y. H., Ren, L. L., Skaggs, T. H., Lu, H. S., Yu, Z. B., Wu, Y. Q., and Fang, X. Q.: Simulation of Populus euphratica root uptake of groundwater in an arid woodland of the Ejin Basin, China, Hydrol. Process., 23, 2460-2469, 2009.

Zomer, R. J., Ustin, S. L., and Carpenter, C. C... Land cover change along tropical and substropical riparian corridors within the Makalu Barun Nationa Parl and Conservation Area, Nepal, Mt. Res. Dev., 21, 175-183, 2001. 